\title{
EFFECT OF TUCK LOOP IN BURSTING STRENGTH OF SINGLE JERSEY KNITTED FABRICS
}

\author{
Rashed $^{1}$, Md. Mahamudul Islam ${ }^{2}$ \\ ${ }^{\text {I} B . S c . ~ E n g i n e e r ~(T e x t i l e), ~ S o u t h e a s t ~ U n i v e r s i t y, ~ I n-C h a r g e ~(C i r c u l a r ~ K n i t t i n g ~ S e c t i o n), ~ B a n g l a ~ J a p a n ~ T r a d i n g ~}$ \\ LTD.Dhaka, Bangladesh \\ ${ }^{2}$ B.Sc Engineer (Textile), Lecturer, Department of Textile Engineering, Southeast University, Dhaka, Bangladesh
}

\begin{abstract}
Strength is an important term any kinds of material and especially for knitted fabric should have its own dimensional stability. We all know it is very difficult to maintain the entire quality parameters in quality test like-Bursting strength test. When we change the design of the fabric by changing cam and needle, then it becomes more difficult to maintain all those parameters. This paper focused on the bursting strength of various derivatives of single jersey knit fabric. Derivatives of single jersey knit fabrics are found by using tuck loops in corporate with knit loops in Wales and course direction. Higher presence of tuck in Wales and course direction affect the bursting strength. From the total analysis it was observed that bursting strength decreases with the increasing of tuck loops in same Wales or course than all knit loop containing fabric (plain single jersey). Bursting strength don't depend on increase or decrease percentage of tuck loops, it depend on how many loops are in same Wales or course. Bursting strength increase and decrease also depend on how many Wales or course used in any design repeat.
\end{abstract}

Keywords: Single jersey fabric, Tuck loop, bursting strength, derivatives of single jersey fabric.

\section{INTRODUCTION}

Textile sector is the biggest sector in Bangladesh and it is also the highest foreign currency-earning sector of Bangladesh. Fabrics are produced mainly by knitting technique and weaving technique. Knit fabric production is easier and quicker then woven technique. Knit garments is growing very rapidly due to less investment, requirement grow of backward linkage \& high profit than woven garments. As it is known that yarn used for knit fabric needs no preparations like warping and sizing, yarn can directly feed on machine after receiving from spinning mills. Feeling of knit fabrics can be modified by introducing miss and tuck loops on its structures where the basic knit structures contains knit loops only. These loops directly affect the bursting strength of knit fabrics. The aim of this paper is to observe the bursting strength variation occurs due to tuck loops increment in Wales and course direction.

A few studies have conducted to predict the bursting strength of knit fabrics.

\section{MATERIALS AND METHODS}

Knit fabric cannot make without knit loop. Knit loop is the base of knitted fabric. Tuck loop and Miss Loop is less stronger then knit loop and they use for design purpose. Use of tuck and miss cams help to produce the derivatives of single jersey. Twelve samples were knitted for this experiment and they are shown here with their cam arrangement and needle arrangement (Figure 1.A, 1.B, 1.C, 1.D, 2.A, 2.B, 2.C, 3.A, 3.B, 3.C, 3.D, and 3.E). 
2.1 Use Tuck Loop in same Wales by Maintaining Percentage (\%) of the Fabrics. (N.B. 30/s yarn) Notation Diagram

\begin{tabular}{|l|c|c|c|}
\hline & \\
\hline
\end{tabular}

2.2 Use Tuck Loop in same Course without Maintaining Percentage (\%) of the Fabrics. (N.B. 30/s yarn) Notation Diagram

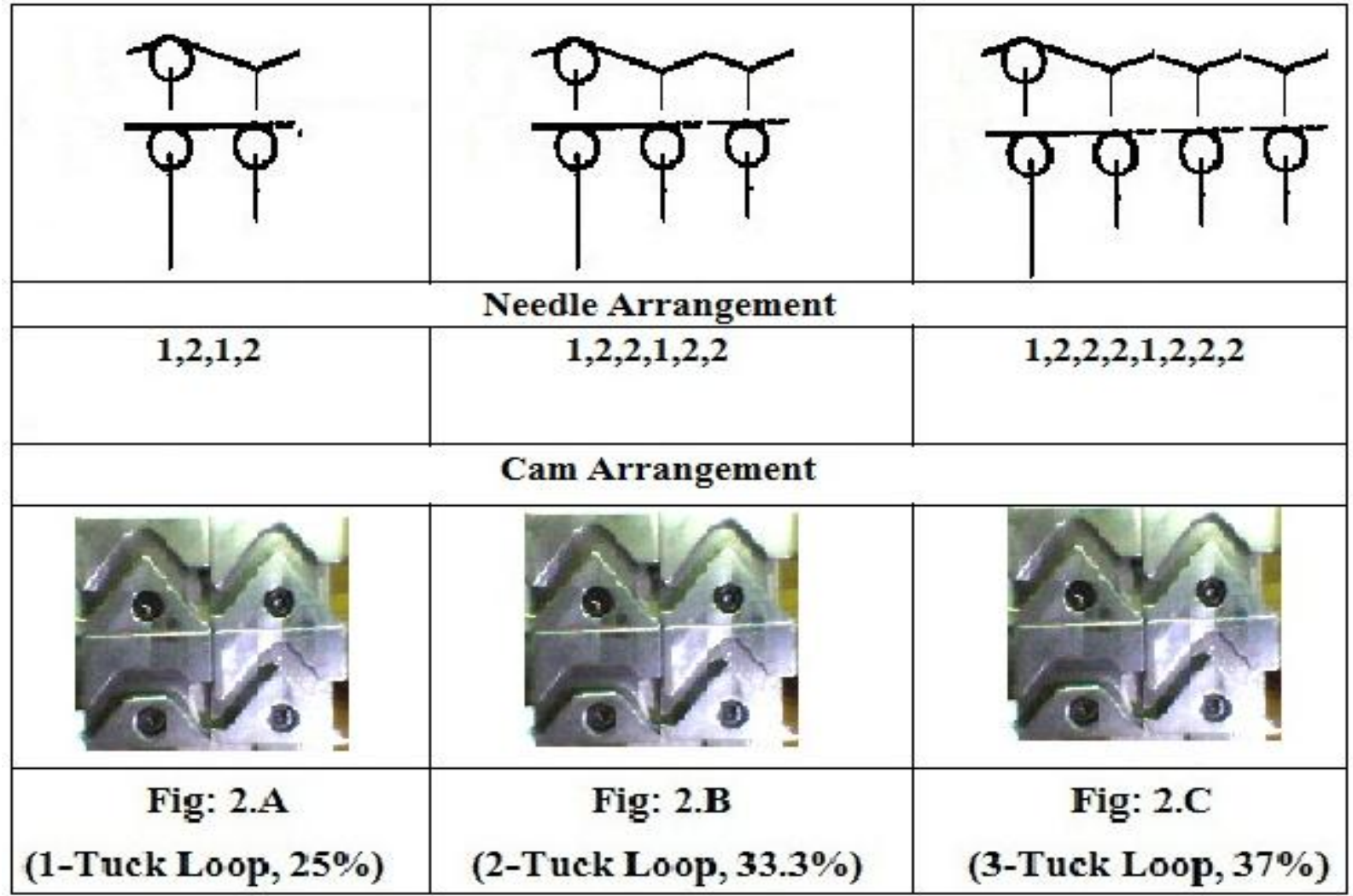


2.3 Use Tuck Loop in various Course \& Wales to Complete Design by Maintaining Percentage. (N.B 40/s yarn)

\section{Notation Diagram}

\begin{tabular}{|c|c|c|c|c|}
\hline \multicolumn{5}{|c|}{ Needle Arrangement } \\
\hline $1,2,1,2$ & $1,2,1,2$ & $1,2,1,2$ & $1,2,1,2$ & $1,2,1,2$ \\
\hline & \multicolumn{3}{|c|}{ Cam Arrangement } & \\
\hline $\begin{array}{l}0.0 .9 \\
0 \times 0.012\end{array}$ & $\begin{array}{l}A N A N A \\
\approx D N A N\end{array}$ & 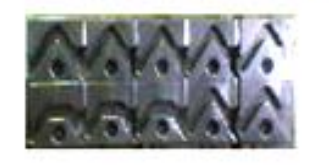 & $\begin{array}{l}\text { Wovat: } \\
\text { adata }\end{array}$ & 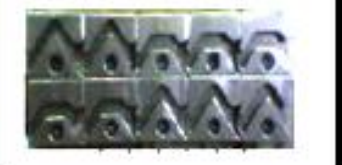 \\
\hline $\begin{array}{c}\text { Fig: 3.A } \\
\text { (10\% Tuck Loop) }\end{array}$ & $\begin{array}{c}\text { Fig: } 3 . \mathrm{B} \\
\text { (20\% Tuck Loop) }\end{array}$ & $\begin{array}{c}\text { Fig: } 3 . \mathrm{C} \\
\text { (30\% Tuck Loop) }\end{array}$ & $\begin{array}{c}\text { Fig: } 3 . \mathrm{D} \\
\text { (40\% Tuck Loop) }\end{array}$ & $\begin{array}{c}\text { Fig: 3.E } \\
\text { (50\% Tuck Loop) }\end{array}$ \\
\hline
\end{tabular}

In our project we have determine the effect of tuck loop in single jersey knitted fabric without any spandex attachment. To make fabrics we used 30/s card yarn in Fig: 1(A,B,C,D), 2(A,B,C) and used 40/s card yarn in Fig: 3(A,B,C,D,E) for fabric, in a 24 gauge circular knit machine having 19 inch diameter and stitch length of $2.70 \mathrm{~mm}$.

After knitting, all the samples were then dyed on a dyeing machine \& finished on tube dryer and tube stenter by maintaining standard procedures. Samples were prepared $15 \times 15 \mathrm{~cm}$ for bursting strength on laboratory and were tested on Digital Bursting machine. At first we have to know about bursting strength tester.

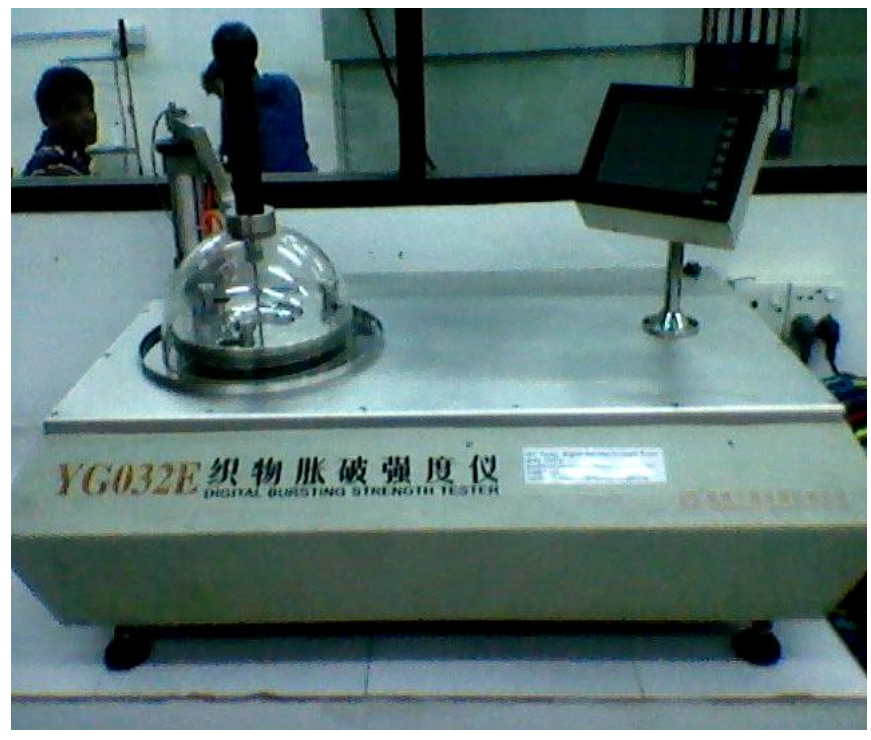

Digital Bursting strength tester

\subsection{Digital Bursting Strength Tester}

It is widely used to measure the resistance to rupture in various materials. Digital Bursting Strength Tester is used to check the bursting strength of fabrics, sheet, papers, etc. 


\section{Specifications}

- Model: YG032E

- Brand/ Company: Fangyuan Instrument (DG) CO. Ltd.

- Origin: China.

- Function: To determine the busting strength of fabric.

Digital Bursting Strength Tester Confirms with following international standards:

- ISO 2758/2759/3303/3689, BS 3424/3137, ASTM 3786, IS 1966

How Digital Bursting Strength Tester works?

- $\quad$ Prepare the sample for test $(15 \times 15 \mathrm{~cm})$

- Mount the specimen between two circular clamps.

- Tighten the specimen with the help of geared handle provided.

- Now apply the increasing pressure (hydraulic).

- The diaphragm is expanded till the specimen ruptures.

- The pressure reading is the Bursting strength in $\mathrm{MPa} / \mathrm{KPa}$ of the given fabric.
The Digital Bursting Strength Tester confirms with the international standards.

\subsection{Data Analysis.}

Table-1, bursting strength test for 10\%, 20\%,30\% and 40\% tuck loop.(Fig: 1.A, 1.B, 1.C, 1.D)

\begin{tabular}{|c|c|c|}
\hline $\begin{array}{l}\text { Percentage } \\
\text { of Tuck } \\
\text { Loop. }\end{array}$ & $\begin{array}{l}\text { Bursting } \\
\text { strength ( KPa ) }\end{array}$ & $\begin{array}{l}\text { Average bursting } \\
\text { strength ( KPa ) }\end{array}$ \\
\hline \multirow[t]{3}{*}{$10 \%$} & 296 & \multirow[t]{3}{*}{294.4} \\
\hline & 296 & \\
\hline & 291 & \\
\hline \multirow[t]{3}{*}{$20 \%$} & 271 & \multirow[t]{3}{*}{263.7} \\
\hline & 264 & \\
\hline & 256 & \\
\hline \multirow[t]{3}{*}{$30 \%$} & 230 & \multirow[t]{3}{*}{226.7} \\
\hline & 219 & \\
\hline & 231 & \\
\hline \multirow[t]{3}{*}{$40 \%$} & 207 & \multirow[t]{3}{*}{210} \\
\hline & 220 & \\
\hline & 203 & \\
\hline
\end{tabular}

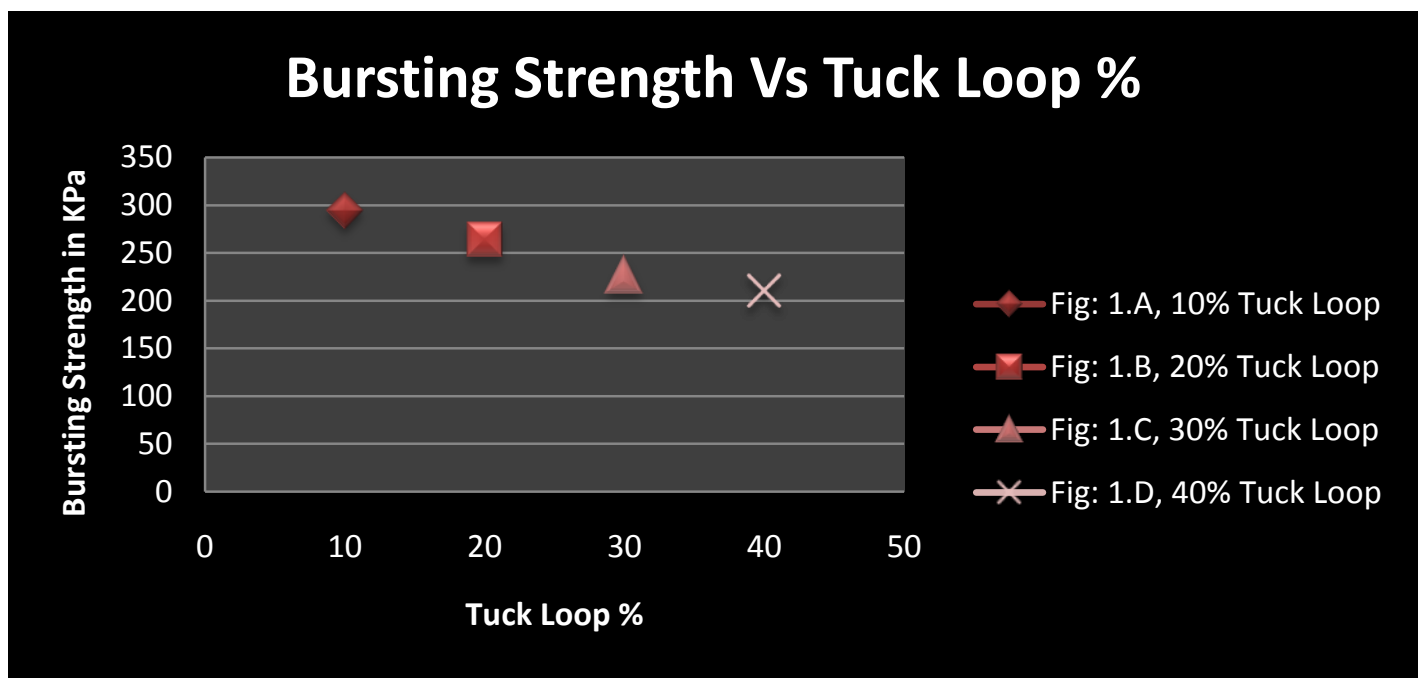

Graph-1 bursting strength test for 10\%, 20\%, 30\% and 40\% tuck loop.

In a ward we can say "when tuck loop in same Wales's increases then bursting strength decreases".

Table-2 Bursting strength test for 1, 2 and 3 tuck loop in same course (Fig: 2.A, 2.B, 2.C)

\begin{tabular}{|l|l|l|}
\hline $\begin{array}{l}\text { No. of Tuck } \\
\text { Loop in } \\
\text { same course. } \\
\text { (Grey fabric }\end{array}$ & $\begin{array}{l}\text { Bursting strength } \\
\text { (KPa) of Grey } \\
\text { fabric. }\end{array}$ & $\begin{array}{l}\text { Average bursting } \\
\text { strength (KPa) of } \\
\text { Grey fabric. }\end{array}$ \\
\hline $\mathbf{1}$ & 317 & 312.3 \\
\cline { 2 - 3 } & 308 & \\
\hline
\end{tabular}

\begin{tabular}{|l|l|l|}
\hline \multirow{4}{*}{$\mathbf{2}$} & 312 & \\
\cline { 2 - 2 } & 304 & \multirow{3}{*}{309.3} \\
\cline { 2 - 2 } & 304 & \\
\cline { 2 - 2 } & 320 & \\
& 303 & \\
\cline { 2 - 2 } & 301 & \\
\cline { 2 - 2 } & 303 & \\
\hline
\end{tabular}




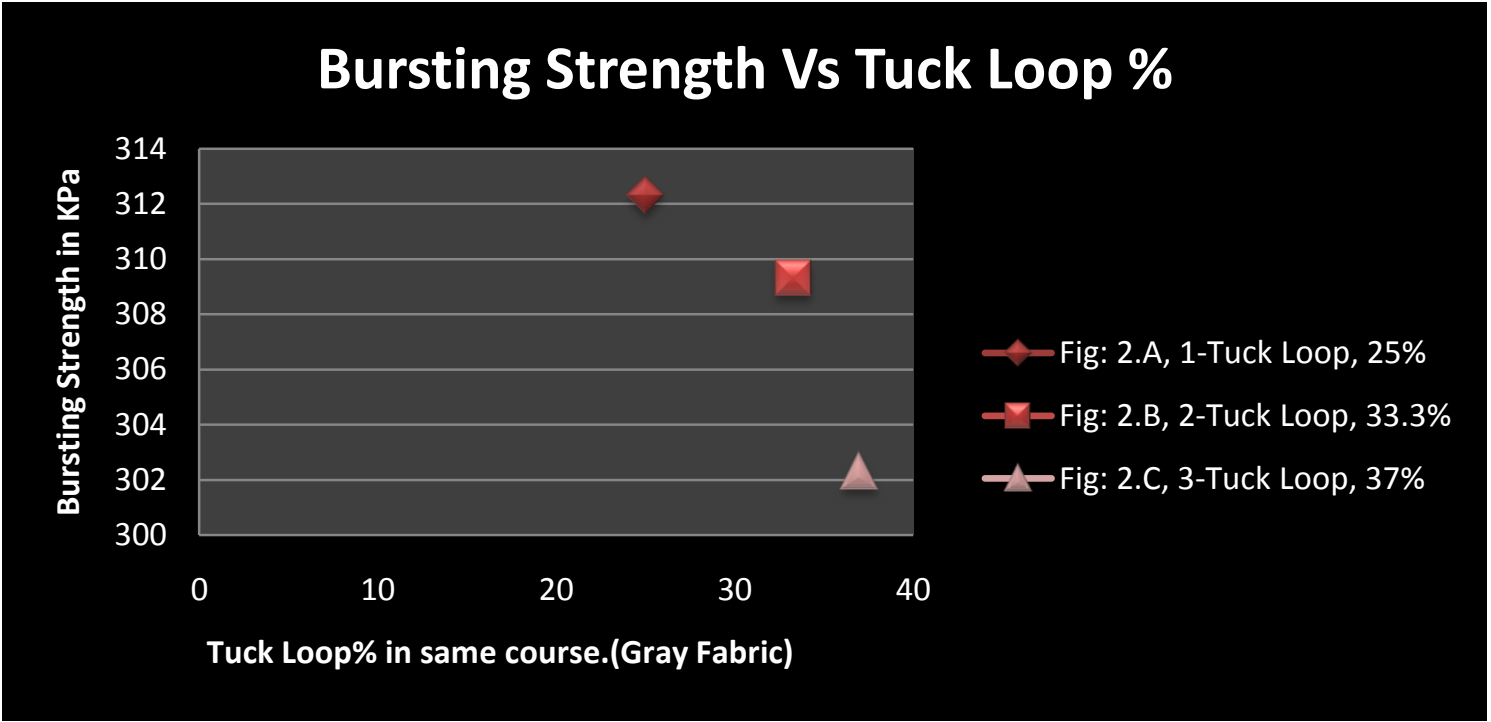

Graph-2 Bursting strength test for 1, 2 and 3 tuck loop in same course

In a ward we can say "when tuck loop in same coarse increases then bursting strength decreases".

Table-3 bursting strength test for $10 \%, 20 \%, 30 \%, 40 \%$ and $50 \%$ tuck loop. (Fig: 1.A, 1.B, 1.C, 1.D, 1.E)

\begin{tabular}{|l|l|l|}
\hline $\begin{array}{l}\text { Percentage } \\
\text { of } \begin{array}{l}\text { Tuck } \\
\text { Loop. }\end{array}\end{array}$ & $\begin{array}{l}\text { bursting } \\
\text { strength } \\
\text { (KPa })\end{array}$ & $\begin{array}{l}\text { Average bursting } \\
\text { strength ( KPa ) }\end{array}$ \\
\hline $\mathbf{1 0 \%}$ & 266 & 261.3 \\
\cline { 2 - 2 } & 254 & \\
\cline { 2 - 2 } & 264 & \\
\hline \multirow{2}{*}{$\mathbf{2 0 \%}$} & 251 & \multirow{2}{*}{244.3} \\
\cline { 2 - 2 } & 259 & \\
\hline
\end{tabular}

\section{Bursting Strength Vs Tuck Loop \%}

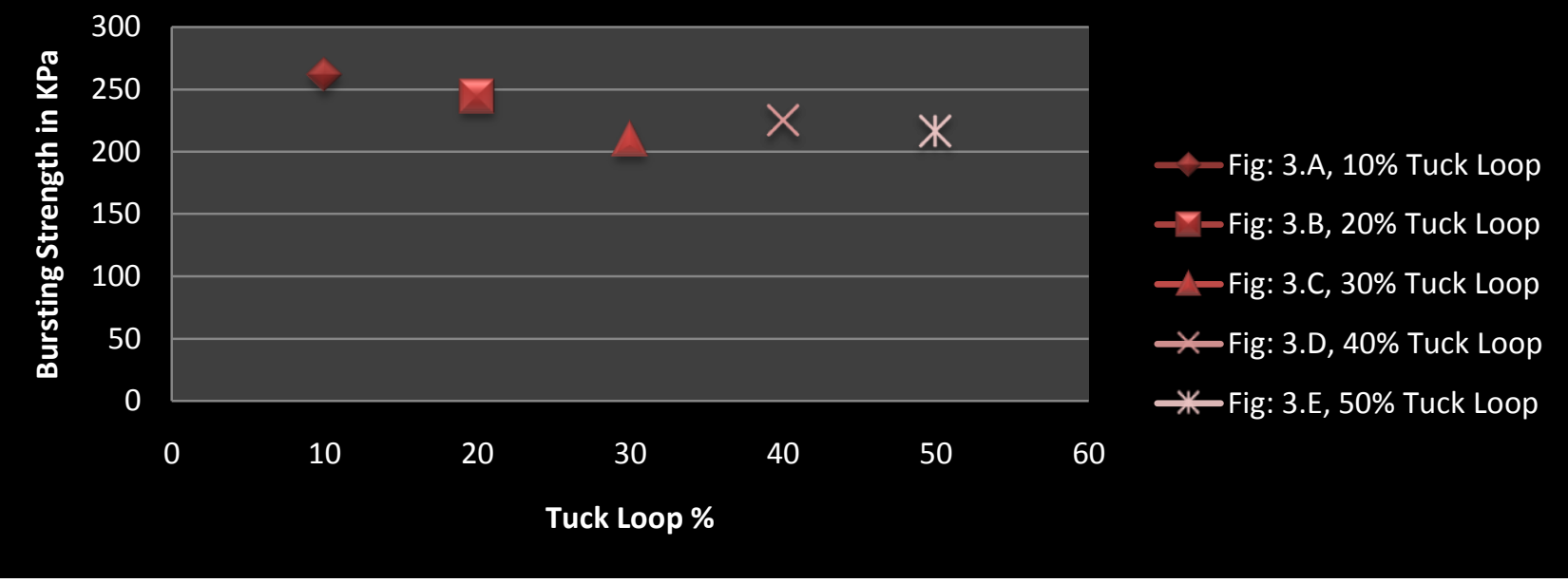

Graph-3 bursting strength test for 10\%, 20\%, 30\% 40\% and 50\% tuck loop. 
From the Table-3 \& Graph-3 we can see that from 10\%$20 \%$ Bursting strength decreases, \& from $40 \%-50 \%$ Bursting strength also decreases but they are upper then $30 \%$.

\section{EXPLANATION}

Now if we want to compare Geaph-1, $2 \& 3$, then we find that in graph-1 and 2 all the value of bursting strength are maintain a sequence like gradually decreases due to tuck loop increase.

So, involvedness of tuck loops decreases the bursting strength. ${ }^{[1]}$

But Graph-3 did not maintain any sequence.

Now we all have a similar question why?

If we look at the chain notation of Fig: $3(\mathrm{~A}, \mathrm{~B}, \mathrm{C}, \mathrm{D}, \mathrm{E})$, we can see that

- $10 \%$ have 1 tuck loop in its repeat (Fig: 3.A).

- $20 \%$ have 2 tuck loops but a knit loop is in the middle of them (Fig: 3.B).
- $\quad 30 \%$ have 3 tuck loops in a Wales one after one (Fig: 3.C).

- $40 \%$ have 4 tuck loops in 2 Wales \& each Wales 2 tuck is decorated one after one (Fig: 3.D).

- $50 \%$ have 5 tuck loop in 2 Wales where 3 tuck in a Wales one after one and other 2 is in other one (Fig: 3.E).

We have tried to find the answer:-

In Graph-3, there is a problem for 30\% tuck loop (Fig: 3.C). We all know, knit fabric is made by loop and knit loop is stronger than others.

So when we apply bursting pressure than all loops elongate in same time. After some time all loops stop elongation, than only tuck loop have to take all those pressure because knit loop is stronger and knit loop quantity is more than tuck loop. At one stage fabric burst (red circle showed in fig: 3.C.1).

Now we can concentrate at $30 \%$ tuck fabric design

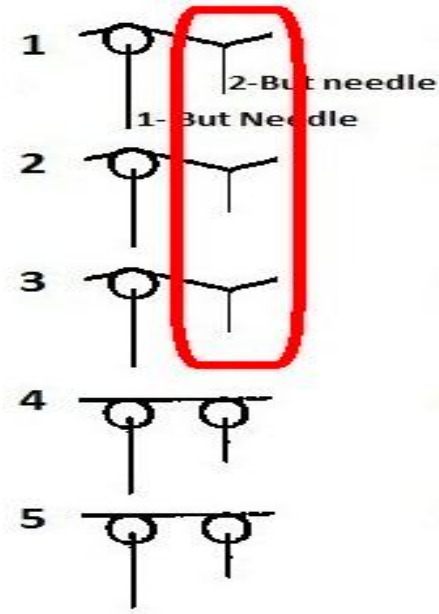

Fig: $3 . \mathrm{C} .1$ (30\% Tuck Loop)

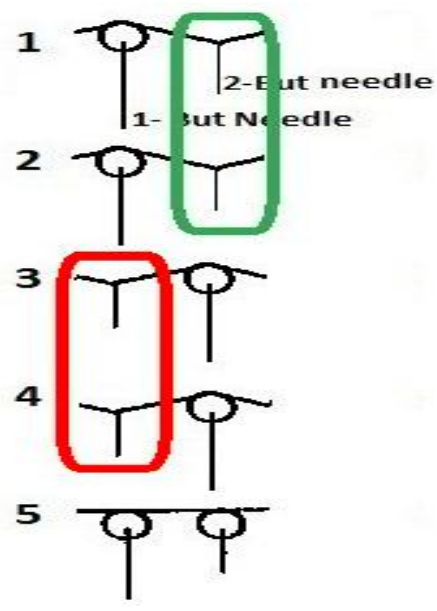

Fig: 3.D.1 (40\% Tuck Loop)

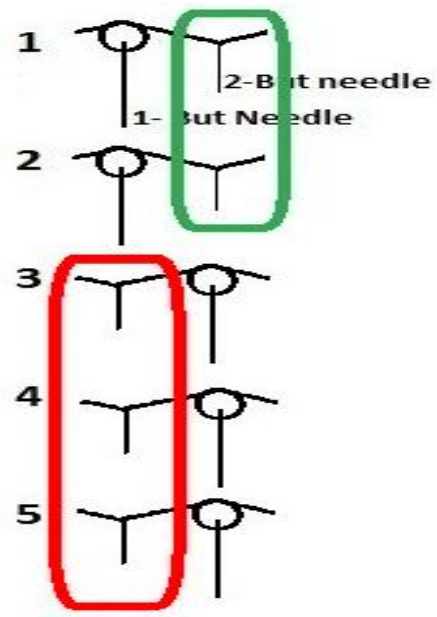

Fig: 3.E -1 (50\% Tuck Loop)
Here 3 tuck in 1 Wales and every side is surrounded by knit loop.

So in Graph-3, 10\%, 20\% and 30\% have maintain the sequence of strength decrease.

Now we have tried to find out why $30 \%$ have decreases more than $40 \%$ and $50 \%$ (Graph-3).

Here, Engr. Shah Alimuzzaman Belal find out, Tuck loop increasing fabric weight and thickness, also increasing fabric width. ${ }^{[3]}$

By following him, we find the GSM and finish diameter of all those fabric in Table-3
Table-4 Tuck loop\% vs. GSM and fabric width

\begin{tabular}{|l|l|l|l|l|}
\hline $\begin{array}{l}\text { Percentage } \\
\text { of Tuck } \\
\text { Loop. }\end{array}$ & $\begin{array}{l}\text { M/c } \\
\text { diameter }\end{array}$ & $\begin{array}{l}\text { Finish } \\
\text { diameter }\end{array}$ & GSM & $\begin{array}{l}\text { Average } \\
\text { bursting } \\
\text { strength } \\
\text { KPa ) }\end{array}$ \\
\hline $\mathbf{1 0 \%}$ & $19 "$ & $17.75 "$ & 115 & 261.3 \\
\hline $\mathbf{2 0 \%}$ & $19 "$ & $18.3 "$ & 124 & 244.3 \\
\hline $\mathbf{3 0 \%}$ & $19 "$ & $20.5 ”$ & 143 & 209.67 \\
\hline $\mathbf{4 0 \%}$ & $19 \%$ & $19.5 \%$ & 134 & 224 \\
\hline $\mathbf{5 0 \%}$ & $19 \%$ & $20.05 \%$ & 138 & 216 \\
\hline
\end{tabular}

But yet we did not reach in any result because of $30 \%$ tuck loop in Table-4, but we get some explanations to find the result and they are- 


\subsection{Explanation- 1}

- We took $15 X 15 \mathrm{~cm}$ sample fabric for bursting strength test, Increase fabric width means less Wales and decrease fabric width means increase Wales in that $15 \times 15 \mathrm{~cm}$ sample.

- So when we take $15 X 15 \mathrm{~cm}$ sample fabric, there $50 \%$ have more Wales then $30 \%$, because $30 \%$ fabric width is bigger than 50\%.(Table-4)

- $\quad$ So, less Wales means less yarn in a course. For this reason when bursting strength applies in the fabric, we find out that $30 \%$ is weaker than $50 \%$ tuck loop fabric.

- So, $50 \%$ is stronger than $30 \%$ because $50 \%$ have another tuck loop area (green circle showed in fig: 3.E.1.) where 2 tuck loops also elongated in bursting force.

- $\quad 40 \%$ tuck loop fabric also go through this logic.

\subsection{Explanation- 2}

- $\quad$ Also the pressure of bursting applied in every loop on that particular area. So, then every loop and whales have to show there elongation power.

- When we see the fig: 3.E.1 and fig: 3.D.1 then we can find out that this design repeat have tuck loop in every Wales. So when we apply bursting force on that fabric, then every Wales will try to show almost nearby or same strength and same elongation. Here they are facing only bursting strength to maintain their shape.

- But when we see the fig., here we can see it have one tuck loop contained Wales and other one is totally knit loop contained. So this fabric shows two different characters in bursting force. Knit loop contained Wales are tried to elongate because knit loops elongation power is more than tuck loop, but tuck loop contained Wales shows opposite character. So in this fabric, tuck loop are facing two different force to maintain their shape.

a. Bursting force.

b. And nearby Wales opposite force.

(This two force is responsible for the difference of bursting strength between the fabric of fig: 3.D.1 and fig: 3.E.1 because fig: 3.E.1 have one tuck loop extra then fig: 3.D.1)

\section{RESULTS}

The result for some knitting parameters of circular knitted fabric are-

- "When tuck loop in same Wales's increases then bursting strength decreases" (Table-1).

- "When tuck loop in same coarse increases then bursting strength decreases" (Table-2).

- Bursting strength increase and decrease also depend on how many Wales or course are considered to make any percentage of tuck loop in any design repeat.(Table-3)
- Bursting strength also depend on fabric width due to tuck loop.(Table-4)

\section{CONCLUSIONS}

Tuck loop is very much important to produce different designed knit fabrics. So we should proper knowledge about tuck loop to get designed fabrics. After the experiment we can come to the following conclusion-

1. When we increase tuck loop gradually in a Wales of a design repeat then bursting strength will decrease gradually.

2. When we increase tuck loop gradually in a course of a design repeat then bursting strength will decrease gradually.

3. To get required bursting strength we should care take about how many Wales or course are considered to make a design repeat.

4. To get required bursting strength due to tuck loop, we should consider fabric width. Because bursting strength also depend on fabric width due to tuck loop.

\section{ACKNOWLEDGEMENTS}

The authors gratefully acknowledge the help \& support from Impress- Rupashi Knit Wears Ltd. of Rupashi Group of Industries Ltd, Fatullah, Narayangonj. Bangladesh and Bangla Japan Trading Ltd, Ashulia, Savar, Dhaka, Bangladesh.

\section{REFERENCES}

[1]. Md. Azharul Islam1; effect of wale wise increasing of tuck and miss loops on bursting strength of single jersey fabric at grey and finish state; IJRET: International Journal of Research in Engineering and Technology eISSN: 23191163 | pISSN: 2321-7308, Volume: 03 Issue: 02 |Feb-2014 [2]. Iyer / Mammel / Schäch; Circular Knitting, Technology Process, Structures Yarns, Quality, second edition. Chapter: $7 \& 8$.

[3]. Engr. Shah Alimuzzaman Belal; Understanding Textile for a Merchandiser, The tuck loop or stitch, page: 408-411.

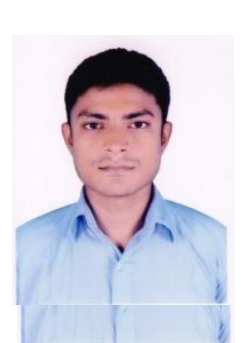

\section{BIOGRAPHIES}

Rashed completed his graduation in B.Sc in Textile Engineering from Southeast University. His interest area in textile is fabric manufacturing technology. He has technical experience over 2 years and currently working at Bangla Japan Trading Ltd. as In-charge of Circular Knitting Division in Bangladesh.

He studied the variations in bursting strength due to tuck loop in fabric design repeat, GSM and Finish Diameter etc.

E-mail: $\quad$ hossain_rara@yaho.com, Skype: rashed.hossain56770, Cell: +8801671857085

Md. Mahamudul Islam completed his graduation from College of Textile Technology, University of Dhaka, 
currently working at Southeast University Dhaka,

Bangladesh as Lecturer, Department of Textile

Engineering, He studied involvedness of tuck loops decreases the bursting strength. 